\title{
Standard Navigation Scheme to Accessibility NCL Apps
}

\author{
Alex de Souza Vieira \\ FACEEL / UNIFESSPA \\ Marabá, Pará, Brasil \\ alexvieira@unifesspa.edu.br
}

\author{
Hedvan Fernandes \\ Pinto \\ LAWS / UFMA \\ São Luís, Maranhão, Brasil \\ hedvanfp@gmail.com
}

\author{
Eráclito de Souza \\ Argolo \\ Campus V / UFMA \\ Pinheiro, Maranhão, Basil \\ esargolo@gmail.com
}

\author{
Léia Sousa de Sousa \\ FACEEL / UNIFESSPA \\ Marabá, Pará, Brasil \\ leiasousa@unifesspa.edu.br
}

\begin{abstract}
This proposal is a suggestion to the Brazilian Association of Technical Standards (ABNT), in NBR 15290, over accessibility Digital TV. The focus is to discuss and establish a standard navigation scheme to accessible NCL applications to be annexed to NBR 15290. This navigation scheme can be used as guidelines for developers to create NCL applications for people with a visual or hearing disability.
\end{abstract}

\section{KEYWORDS}

Standard navigation scheme, accessibility, development guidelines, iDTV applications, user experience.

\section{Introdução}

No Brasil, segundo pesquisa do Instituto Brasileiro de Geografia e Estatística (IBGE, 2010), há cerca de $0.27 \%$ pessoas com deficiência visual, enquanto o total de pessoas com deficiência auditiva é cerca de $0.18 \%$. Embora essa porcentagem pareça pequena, ao juntar o total de pessoas com deficiência visual leve e deficiência auditiva leve percebemos que mais de $15 \%$ da população, ou seja, mais de trinta milhões de pessoas tem alguma dessas deficiências.

Esta proposta pretende discutir a padronização de um esquema de navegação, para TV Digital interativa (TVDi), fundamentada no uso das teclas de navegação do controle remoto, especificamente as setas de navegação e a tecla ENTER, para facilitar a essas pessoas o uso desses aplicativos, com o intuito de lhes oferecer uma melhor experiência de uso.

Dessa forma, as pessoas com deficiência visual poderiam ter mais autonomia para alterar, por exemplo, a audiodescrição da cena para audiodescrição de cenário ou dos personagens. Isso pode ser feito, de acordo com o aplicativo NCL (Nested Context Language) (SOARES NETO, et al), no momento que o usuário seleciona a tecla up do controle remoto da TV.

De outra forma, usando um outro aplicativo NCL, as pessoas com deficiência auditiva, poderiam selecionar a mesma tecla para

In: Future of Interactive Television Workshop (V WTVDI), Rio de Janeiro, Brazil. Anais Estendidos do Simpósio Brasileiro de Sistemas Multimídia e Web (WebMedia). Porto Alegre: Sociedade Brasileira de Computação, 2019.

(C)2019 SBC - Sociedade Brasileira de Computação.

ISSN: 2596-1683 alternar entre as áreas de exibição da janela de LIBRAS (Língua Brasileira de Sinais) e a área restante onde é exibido o conteúdo principal.

O controle remoto de um aparelho de TV possui teclas que geralmente se destacam, quer seja por suas posições, quer seja por suas dimensões. Isso pode ser observado nas teclas de navegação (representados pelas setas direcionais: up, down, left e right), as quais se encontram no entorno ou próximas da tecla Enter/OK e a própria tecla Enter/OK (com as suas dimensões maiores), conforme é apresentado no esquema da Figura 1.

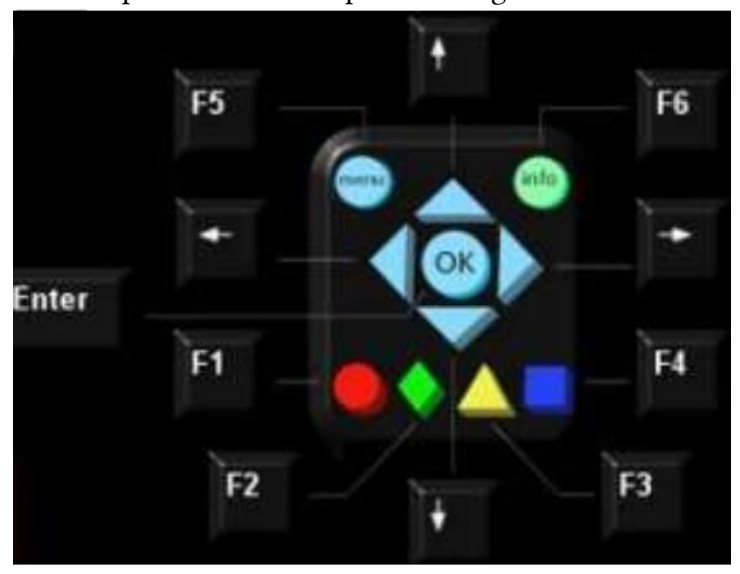

Figura 1: Teclas que se destacam no controle remoto de um aparelho de TV tradicional (Fonte: GingaDF)

A Figura 1 apresenta o conjunto de teclas que podem ser identificadas, visualmente, por surdos e videntes e, de forma tátil, podem ser identificadas por cegos. Por esse motivo, esta proposta considera viável o seu uso para estabelecer um esquema de navegação, baseado nessas teclas, capaz de oferecer uma padronização consistente para o desenvolvimento, ou consumo, de aplicativos NCL assistivos.

Outras teclas que geralmente se destacam, no controle remoto, são as teclas de atalho dispostas nas cores vermelha, verde, amarela e azul, nesta ordem, as quais também podem ser, eventualmente, utilizadas para habilitar ou desabilitar um determinado aplicativo assistivo, de acordo com a necessidade do usuário. 
Observa-se que, apesar da impossibilidade da identificação visual por cegos, a sequência dessas teclas é imutável e, portanto, eles são capazes de identificá-las.

\section{Standard navigation scheme proposed to accessibility NCL apps}

Esta proposta consiste em discutir um esquema de navegação específico para aplicativos NCL assistivos, que possa ser adicionado à recomendação à norma brasileira NBR 15290 (2005), baseado principalmente nas setas navegacionais do controle remoto tradicional, visando auxiliar no processo de desenvolvimento ou consumo desses aplicativos.

Ela atende ao contexto de desenvolvimento (em tempo de codificação), trazendo mais facilidade para os desenvolvedores. A padronização então tornaria as aplicações assistivas mais populares junto ao público alvo, uma vez que a curva de aprendizado em relação aos recursos disponibilizados pelos desenvolvedores aos seus usuários finais seria mitigada em curto espaço de tempo para aquele público alvo.

Inicialmente, recomenda-se a apresentação de um nó de mídia, com uma indicação sonora e visual, para representar a disponibilidade de um aplicativo NCL assistivo, logo que o conteúdo audiovisual comece. A apresentação deste aplicativo deve ocorrer através da seleção da tecla ENTER.

$O$ esquema de navegação aqui proposto considera dois momentos distintos: utilizando as setas navegacionais; e utilizando teclas de atalho.

Quando utilizando as setas navegacionais, o desenvolvedor deve estabelecer que todos os nós de mídia associados ao papel de seleção possam ser percorridos, horizontalmente ou verticalmente no aplicativo, a partir das ações de movimento (moveUp, moveDown, moveLeft e moveRight) atribuídas aos descritores, conforme é apresentado na Figura 2.

À princípio, sugere-se que essa navegação seja iniciada próximo ao topo e à esquerda da tela - como exemplificado na região de referência (region="initialReference"), da Figura 2(a), e que ocorra na posição vertical, no sentido de cima para baixo possibilitando percorrer todos os objetos de mídias que podem ser selecionados.

Em seguida, para cada nó de mídia selecionado (A, B ou C, da Figura 2(a)), sugere-se que a navegação nos seus submenus (e.g. a1, a2, ... an) ocorra inicialmente na direção horizontal, e no sentido da esquerda para a direita, conforme é apresentado na Figura 2(b), possibilitando percorrer os objetos de mídia que podem ser selecionados - quando houver.

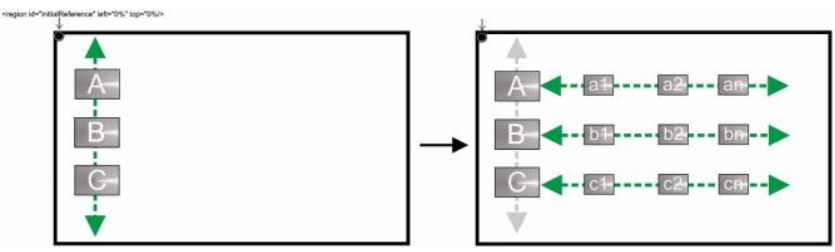

Figura 2: Esquema de navegação proposto (Fonte: autoria própria)
A navegação pelos menus ou submenus deve ser acompanhada pela audiodescrição dos itens selecionados no momento na forma de uma mídia de áudio, informando o seu título. Ao acionar a tecla ENTER deve entrar na opção selecionada, quando houver. Uma vez dentro de um submenu, recomenda-se o uso de uma tecla para retornar ao menu superior.

Quando utilizando teclas de atalho, o desenvolvedor deve primar pela ordem padrão (vermelho, verde, amarelo e azul) para habilitar ou desabilitar, respectivamente, aplicativos assistivos para pessoas com deficiência visual, deficiência auditiva, legendas (subtitles) e reapresentação do menu principal.

Sugere-se que, ao selecionar uma vez a tecla de cor vermelha, o usuário habilite a apresentação de algum aplicativo assistivo para pessoas com deficiência visual para que possam, por exemplo, controlar aspectos da audiodescrição. Ao selecionar novamente a tecla vermelha, o aplicativo deve ser desabilitado.

Quando o usuário selecionar a tecla de cor verde, então um aplicativo assistivo para pessoas com deficiência auditiva deve ser habilitado para que possam, por exemplo, controlar as dimensões da região do intérprete de LIBRAS. Quando o usuário selecionar novamente a tecla verde, esse aplicativo deve ser desabilitado.

Quando a tecla de cor amarela for selecionado, outros idiomas devem ser alternados entre si (se houver transmissão de legendas em outros idiomas), na ordem de apresentação de legenda em um idioma a cada vez que a tecla for selecionado. A última seleção deve corresponder à ação de desabilitar a apresentação da legenda.

Quando a tecla de cor azul for selecionada pelo usuário, o menu principal deve ser apresentado novamente para ele.

Enfatiza-se que esta proposta colabora para o processo de desenvolvimento de aplicativos assistivos para TVDi, pois desenvolvedores usando o ambiente GINGA-NCL, ou mesmo GINGA-J, teriam em mãos um conjunto básico de recomendações, com indicações de quais elementos do dispositivo de entrada utilizar, o que pode ser estendido ou adaptado também para outros dispositivos de entrada acoplados à TV como, por exemplo, teclados similares ao de computador.

Por fim, enfatiza-se que essa é uma proposta importante para atender a pessoas com deficiência, ou ainda com mobilidade reduzida, porque tal padronização tornaria mais inclusivo e provavelmente mais fácil o consumo de conteúdos interativos, pois assim, aprenderiam a utilizar a maioria dos aplicativos assistivos.

\section{REFERÊNCIAS}

[1] SOARES NETO, Carlos de Salles; SOARES, Luiz Fernando Gomes; DE SOUZA, Clarisse Sieckenius. The nested context language reuse features. Journal of the Brazilian Computer Society, v. 16, n. 4, p. 229-245, 2010.

[2] IBGE (2010), Brasileiro de Geografia e Estatística. População residente por tipo de deficiência, segundo a situação do domicílio, o sexo e os grupos de idade Amostra - Características Gerais da População. 2010. Disponível em: https://sidra.ibge.gov.br/tabela/3425\#notastabela. Acessado em: 08 de agosto de 2019.

[3] GINGA DF. Como estruturar um ambiente seu desenvolvimento para o middleware GingaNCL. Fonte: http://www.gingadf.com.br/blogGinga/. Acessado em: 10 de agosto de 2019.

[4] BNT NBR 15290 (2005). Acessibilidade em comunicação na televisão. Disponível em www.crea-sc.org.br/portal/arquivosSGC/NBR\%2015290.pdf. Acessado em 10 de agosto de 2019. 